KATARZYNA MARAK

Cultural Studies

Nicolaus Copernicus University in Torun, Poland
Images

vol. XXIX/no. 38

Poznań 2021

ISSN 1731-45OX

\title{
Independent horror games between 2010 and 2020: Selected characteristic features and discernible trends
}

\begin{abstract}
Aвstract. Marak Katarzyna, Independent horror games between 2010 and 2020: Selected characteristic features and discernible trends. "Images" vol. XXIX, no. 38. Poznań 2021. Adam Mickiewicz University Press. Pp. 175-190. ISSN 1731-450X. DOI 10.14746/i.2021.38.11.

The focus of this article are independent digital horror games and their characteristics; the goal was to briefly describe the independent horror scene and highlight some of the artistic and technical trends which manifest themselves in the titles belonging to that scene. Due to the sheer number of available games, the scope of the paper is narrowed down to only selected characteristics and trends distinguishable in game texts published between the years 2010 and 2020. The aim of the article is to present a selection of observations and conclusions concerning the independent games scene and to hopefully point to what these games can tell scholars about the way both the players and the developers perceive the horror genre.
\end{abstract}

KEYwORDs: independent horror games, the 2010-2020 decade, trends in indie horror games, indie horror

In 2010, a game associated with the burgeoning of the independent horror games scene was released: Amnesia: The Dark Descent. Exactly ten years later, Amnesia: Rebirth (2020) came on the market, marking a full decade of widespread popularity of independent horror games. Digital horror games enthusiasts can choose from a plethora of independent titles, now available to a much greater extent than in the previous (2000-2010) decade, partly due to the accessibility of means of production and distribution of such texts.[1] The flourishing indie scene is highly heterogenous, encompassing an abundance of diverse game texts. It is important to note, however, that "independent" in the context of games is a term both broad and vague, difficult to define according to either aesthetics, gameplay quality or price. As a result, no single quantifiable aspect of a game makes it "independent" in the eyes of the players, but some specific, hard to define quality of either artistic audacity or disregard for convention. The least ambiguous and the most useful criteria for identifying independent texts that have been established thus far seem to be the ones listed by Maria Garda and Paweł Grabarczyk; for a game to be regarded as independent, the 
creator or creators of the given title must be autonomous in at least two of these three aspects: financial resources, creative expression, and the ability to make their work available to the public.[2] These three domains of creative liberty allow for the exploration of the controversial, the taboo, and the bizarre, through implementation of diverse virtual environments constructed in an rich variety of styles, aesthetics and conventions, where technology takes second place to the artistic vision of the developer or developers. [3]

The focus of this article are independent horror games published between the years 2010 and 2020 and their characteristics, as well as any propensities that become apparent upon closer analysis[4]; due to the sheer number of available game texts, only selected characteristics, such as aesthetics, storytelling devices and mechanics, scare tactics, as well as the overall premise and thematic focus of the games, will be discussed. The games themselves will also be limited to single-player titles available at no cost or retailing for less than $\$ 15$ on platforms such as Steam, Itch.io or gamejolt,[5] and small in scope (understood as the time necessary to traverse the game world and complete the game[6]), ranging from five minutes to a couple of hours. The text does not aim at formulating a clear, elaborate division of independent game texts, but rather to present a selection of observations and conclusions concerning the independent games scene and the trends which emerge within it.

Graphic style and aesthetics
This section concerns the visual language of games and the design of virtual environments. Independent games tend to use a variety of ways of projecting the player into the game world, [7] ranging from traditional $3 \mathrm{D}$ graphics, or a number of retro styles, to experimental or stylized representations.

The vast majority of small indie horror games make use of fully-rendered $3 \mathrm{D}$ graphics, ranging from decidedly realistic representations, such as Paranormal Entities (2020), to very austere or crude styles, like Baldi's Basics (2018). The most common iteration of that approach is the regular, realistic three-dimensional virtual environment; the de-
[2] M.B. Garda, P. Grabarczyk, Is every indie game independent? Towards the concept of independent game, "Game Culture Studies" 2016, vol. 16, no. 1.

[3] K. Marak, M. Markocki, D. Brzostek, Gameplay, Emotions and Narrative: Independent games experienced, Pittsburgh 2019, pp. 17-18.

[4] Some data and observations concerning independent digital horror games published between 2010 and 2015 have also been discussed in Chapter Five of Aspekty funkcjonowania gier cyfrowychwe wspótczesnej kulturze. Studia przypadków (K. Marak, M. Markocki, Toruń 2016, pp. 94-116); however, any context in which they are mentioned in this text is consistent with the current analytical perspective. [5] Due to length limitations, only a couple of examples will be provided per any raised point. For the same reason, the entire subgenre of rpg-maker horror, despite its continuing and influential presence on the independent horror scene, is not going to be discussed - although it is important to note that the continued popularity of representative titles such as Witch's House (2012), Ib (2012), Mermaid Swamp (2013), or Sandman (2014) has not stopped inspiring new titles.

[6] J. Bizzocchi, J. Tanenbaum, Well read: Applying close reading techniques to gameplay experiences, [in:] Well Played 3.o: Video Games, Value and Meaning, ed. D. Davidson, Pittsburgh 2011, p. 300.

[7] B. Perron, Horror Video Games: Essays on the fusion of fear and play, Jefferson 2009, p. 97. 
picted world tends to comprise predominantly abandoned buildings, forests and caves, and sometimes abstract, alien landscapes; a variation of $3 \mathrm{D}$ realistic graphics is a virtual environment embellished with a VHS effect filter, meant to make the gameplay resemble the experience of watching a VHS tape, as can be seen in The Tape (2016), or V.H.S. (2017).

Another take on graphics in independent horror games is a retro appearance, where the virtual environment is rendered to resemble a particular graphic style, for example MS-DOS design or an old-fashioned game console visuals. This trend is meant to appeal to the players' nostalgia related to certain past experiences, and tends to be enjoyed more by those familiar with the time period in which the given graphic style was prevalent. The nostalgic aesthetic associations of early consoles days are especially visible in games like Helltown (2017), Paratopic (2018), or Night Ripper (2018), where the irregular, jagged shapes of characters and objects and distinct textures add to the uncanny atmosphere.[8] Another approach to retro graphics is the $3 \mathrm{D}$ pixelated style, observable in games like HIDE (2011), First Winter (2018), or Russian Sleep Experiment (2019), which appeals to similarly nostalgic perceptions, but in a more abstract way, being more of an artistic choice than an attempt to emulate something specific from a set period of time. In contrast, games employing $2 \mathrm{D}$ pixelated graphics, like The Restless (2017), The Last Train Home (2020) or House (2020), tend to be - due to the nature of that particular style - the most homogeneous aesthetic trend, emphasizing utility over realism and beauty. However, the lack of visible details can effectively be used to enhance the uncanny atmosphere and the potential of scare tactics.

There is one more aesthetic design discernible among independent horror games, which is probably both the most heterogeneous and rare among the discussed graphic styles. Sometimes the developers opt for highly stylized artful conception of their text, ranging from line art to cel shading. Graphics based on hand-drawn lines are featured in, for example, Bad Dream: Graveyard (2013) or My Friend Is A Raven (2019); a similar approach is the paper cut-out format, like in A Short Creepy Tale: 7 PM (2020). The virtual environment can be rendered as monochromatic, as evident in 1916 Der Unbekannte Krieg (2011) or Which (2010), or, on the contrary, vividly colorful, like in Lorelai (2019). Some designs are remarkably detailed, such as Now You See (2019), while others are rudimental to the extreme, as evident in Sonar (2011). The diversity of aesthetic depictions of game worlds in these games allows the creators to lend their work a distinct quality, enhance symbolic elements or convey abstract ideas.[9]

[8] The unnatural, distorted shapes and proportions of human and animal characters as well as the unrealistic, seemingly unfinished textures both contribute to the effect of defamiliarization: the familiar appearing strange and the strange becoming increasingly familiar as the player's "sense of solid reality" destabilizes and the "distinctions between the imagination and reality [is] erased within the uncanny". G. Wisker, Horror Fiction: An introduction, New York 2005, p. 231.

[9] A good example of creators making specific use of aesthetics is Which, where the stylised, minimalistic 
Storytelling tools and devices
The majority of narratives employed by independent horror games tend to revolve around some horrifying event or process - murder, tragic death, torture or genetic experimentation - the consequences of which constitute the immediate threat in the form of a haunting or a pursuing monster.[10] Although virtually all horror games include some sort of story, the significance of that story can vary from being the very essence of the gameplay experience to a mere makeshift backdrop to the mechanics and visuals. The storytelling strategies most often implemented in independent horror games cover the push and pull types of narrative[11], environmental storytelling, [12] and narrative design.[13]

The environmental storytelling in small scope independent horror games tends to be rather heavy-handed. In some cases, it enhances the desired effect, as evident in Peridium (2017) or The Swine (2020), but in the case of weaker games, the overabundance of traces may result in chaos. For example, the developer will occasionally fill the location with an amount of blood and body parts that is just unreasonable and excessive in comparison to any events that might have logically taken place before the player arrived at the location, as can be observed in virtual environment rendered exclusively in black and white allows for a symbolic rather than graphically gruesome presentation of the severed head and the gaping hole in the chest of the mysterious woman; similarly, the visual choices in Close Your Eyes go beyond simple aesthetics, as closing the avatar's eyes literally allows the player to see that which is beyond sight, and represents the juxtaposition of the concepts of "fabricated facade" and "underlying truth."

[10] Interestingly, many of those narratives share characteristics with postmodern horror film narratives. They begin with a "violent disruption of the normative order by a monster, which can take the form of a supernatural or alien, a deviant transformation from within, a psychotic, or a combination of these forms," and devote much attention to the monster's rampage, which the protagonists and other characters in the game are unable to effectively resist with violence of their own - this, in turn, leads to the lack of narrative closure and a number of open ending forms (Pinedo 2004: 89-90). In the three most common ones the monster either triumphs (which can be seen in Keep Them Below, 2015), or is eluded or temporarily subdued (like in No One Lives Under The Lighthouse, 2020), or the final outcome is uncertain (as is the case in Alone, 2016). Cf. I. Pinedo, Postmodern elements of the contemporary horror film, [in:] The Horror Film, ed. S. Prince, New Brunswick 2004, pp. 85-117.
[11] Push narrative and pull narratives are the two disparate types of scripted narrative; the "push narrative" refers the player being exposed to the information the game creators wanted to convey, without having any say in the matter, whereas "pull narrative" concerns the information and narrative elements embedded in the virtual environment, which the player must actively seek out (this may result in the player failing to discover parts of the narrative, but it also encourages exploration, and thus facilitates agency). G. Calleja, In-game: From immersion to incorporation, Cambridge 2011, p. 122.

[12] Environmental storytelling concerns game design elements which provide narrative context, making the story "directly relevant to gameplay beyond world-building and backstory exposition"; traversing the space of the game world, the player observes the virtual environment, attempts to makes sense of it, and interpret it, thus creating a narrative. C. Fernández-Vara, Game Spaces Speak Volumes: Indexical storytelling, <http://www.digra.org/digital-library/ forums/6-think-design-play/>, accessed: 10.08.2019. [13] Narrative design refers to the way in which the space of the game is designed - the player is expected to navigate that space in a certain way, contributing to constructing a story; the narrative design concerns the actual location, puzzles and objectives within it, as well as characters and objects. C. Fernández-Vara, Introduction to Game Analysis, New York - London 2015, p. 159. 
The Janitor (2016). Sometimes, the elements of the virtual environment are not only exaggerated, but also mismatched; the players will encounter random objects in the depicted world which have no rational justification for being there, such as a single lamp in a concrete maze in Forgotten Tapes (2019) or a potted plant in an empty room of a museum in The Final One (2016). Sometimes mismatched assets are mere elements of the background, but in some cases, they are crucial to the gameplay, such as the eponymous pages inexplicably pinned to the trees in Slender: The Eight Pages (2012), or light bulbs scattered all over a field in Aloorees (2019).

In most cases, the indie texts tend to rely on the traditional push or pull narrative[14] or, occasionally, on the combination of both, like in the game Serena (2014). A push narrative usually takes the form of narration delivered either by recorded dialogue or through paragraphs of text displayed on the screen, usually at the beginning of games such as Filthbreed (2019) or Devout (2019); sometimes, the villain's expository monologue, like in Room 404 (2016) or The Final One, is used. Conversely, the most popular form of pull narrative appears to be notes and journal pages - also, on occasion, audio recordings -scattered around the environment. The notes and journals range from poorly written, like in Fragments (2019) or Perdita (2019), to quite eloquent and convincing, as seen in The Society (2016) or The Journal of Randolph Warren Carter (2016).

There are also independent games which rely exclusively on the narrative design; they influence the emergent narrative through the design of the virtual environment, prompting the player to traverse it in a specific manner, performing specific actions on the way. $E R$ or Wake Up (2016) are the simplest examples of this approach, while its more sophisticated execution can be observed in Notes of Obsession (2016), where the emergent narrative is formed by the player's actions and movements, guided by the design of the space of the game and the puzzles required to progress, which involve a music box and symbols appearing on the walls.

This section is devoted to gameplay mechanics, understood as both an inherent part of the design of the gameplay experience and as artistic expression. The mechanics employed by independent games tend to be closely related to the overall premise of the game.

The overwhelming majority of horror games involve a human avatar traversing a visually represented virtual environment[15] who is capable of some degree of interaction with selected elements of that

[14] G. Calleja, op.cit., pp. 123-124.

[15] There are, of course, digital games which rely solely on sound, being built around complete auditory interfaces meant to be played without graphic representation (e.g. BlindSide 2012). The confusion and awkward nature of in-game mobility brought about by sightless exploration result in the players' disorientation and tension, contributing to the horror atmosphere of the given game. Cf. K. Marak, M. Markocki, D. Brzostek, op.cit., pp. 78-79. 
environment. The actions that the player can perform can be limited to literally walking around and picking up notes or receiving messages, as it happens in Moon Sliver (2014), I Remember This Dream (2015), Disconnected (2017) or Late Night Wanderer; or be as complex as interacting with the environment, managing resources, solving puzzles and fighting off enemies at the same time, like in Frostbite (2017), The Glass Staircase (2019) or Simulacrum (2019). The most common set of actions in independent horror games expected by the players consists of walking and running, examining items, and controlling some sort of light source to penetrate the ever-present darkness; there are few games which lack these particular mechanics. Combat and resource management - namely replenishing batteries for the flashlight or taking medication, like in Despair (2015), The Diving Bell (2020) or The Last Light (2016) - are also typical features of independent horror games. Similarly, stealth is a common mechanic, particularly associated with games revolving around the proximity of monsters, such as Albedo (2019), Monstrum (2015) or Tanggal (2018).

With regard to the gameplay premise, a significant number of independent horror texts revolve around simple traversing the gamespace, accompanied by elements of the pull narrative. Such games, usually classified as walking simulators, focus on exploring the game world with emphasis on observing it; the horror aspect of the game is explored through the use of horrific setting, a tense, eerie atmosphere, and sometimes also well-timed startle effects; examples of such games are Tonight You Die (2015) or Anatomy (2016).

Another easily recognizable and well-known gameplay premise is the survive-the-night model. This particular premise has been popularized by Five Nights at Freddy's (2014), which, over time, spawned numerous clones, such as One Night at Flumpty's (2015) or The Dolls (2016). The mechanics revolve almost exclusively around keeping the character alive for a fixed period of time while either resisting or withstanding the repeated attacks of an enemy, while at the same time observing specific, complex rules which determine survival. Later games based on the survive-the-night mechanic introduced some variation into the model, as evident in Boogeyman (2015), which features the monster trying to enter the room, or Night Blights (2015), where the enemies in the different rooms must be fed toys.

Although puzzle games are not very common in the horror genre, there are titles - such as Cozy (2018) or Buddy (2020) - which employ point-and-click mechanics and focus on exploring the game world with an emphasis on examining it; the imagery and puzzles themselves are horror-themed, and tend to involve gruesome objects or actions. Some puzzle horror games convey a story, as evident in Deep Sleep (2013), Shiver (2017), or Forgotten Hill: Mementoes (2018), while other titles focus entirely on abstract puzzles involving completely unrelated objects and actions - such as cutting a deer's antlers with a knife to obtain blood for an alcoholic drink - and do not offer any ludically or emotionally 
meaningful ending, as can be seen in Bad Dream: Graveyard (2013) or Rusty Lake Hotel (2015).

Another gameplay type which has emerged on the independent horror games scene and maintained a continued presence there is the metafictional sub-genre, represented by games like Pony Island (2016) or Horns of Fear (2018). Such texts place particular emphasis on the mediated nature of games as a medium; the horror effect is produced by inducing in the player an uneasiness caused by the game's interactive nature appearing to extend beyond the actual reach of its software. Games of this type will also occasionally break the fourth wall by engaging the player with what is implied to be a self-aware game software as an entity composed of the data stored on the player's hard drive, as evident in Imscared (2012) or Mono (2017). Sometimes, such games will additionally multiply and juxtapose aesthetic and ludic conventions for a more striking effect, as can be seen in Submission (2020).

Some independent titles, however, experiment with a more creative approach to the way in which the concept of the game is expressed. Due to the aforementioned fact that virtually all independent horror games employ audiovisual representation, the majority of creative strategies and mechanics revolve around avoiding being seen, watching enemies or either not being able to see or rendering things (objects, enemies) visible.[16] There are numerous games which either focus mechanic-wise on watching the enemy, or include a similar mechanic in order to prevent them from attacking, such as SCP: Containment Breach (2012), Emily Wants to Play (2015) or Statues (2015). In games like these, the player does not engage in combat, but must incorporate that particular mechanic into their strategy as they play, which affects the way they explore and navigate the game space.

Another situation is providing the player with a skill, as can be seen in The Tithe (2018), or an object, like in Notes of Obsession, which allows them to see and either pursue or avoid certain paths and places, thus granting them the knowledge necessary to complete the game. An intriguing take on this tactic is the reversal of the mechanic, whereby the player is given the possibility to close their character's eyes in order to see something important or avoid danger, for example in games Under the Bed (2018) or Close Your Eyes (2018). Apart from prompting the players to coordinate two virtual environments describing the depicted world of the game, this mechanic is particularly interesting in the context of the horror genre, where temporary vulnerability stemming from the inability to face the danger contributes to the tension and mood. The exact opposite of the temporary surrender of sight is a struggle for sight, which is sometimes used in certain independent horror titles featuring blind or blinded protagonists, like Lurking

[16] Some of these ideas and strategies gain traction and appear in high budget productions, as can be seen in Perception (2017), which uses the same echolocation mechanics as Lurking or Sightless; sometimes, on the other hand, it is the independent titles which adapt mechanics from mainstream, high budget games, as it is the case with the mechanics of sightjacking in Siren (2003) and Eyes (2013). 
(2014), Sightless (2014), or Ripple (2020). Such game usually plunge the protagonist into complete or almost complete darkness, forcing them to continuously produce sounds (such as footsteps or tapping a cane on the floor), which in turn bring the immediate surroundings of the avatar into focus; however, the image fades just as quickly, leaving the player lost once again. As a result, the players experience a situation in which they need to consciously perform an action which, it is worth noting, in some games, such as Stifled (2016), will put them in danger, as the enemy can locate them by listening.

\section{Scare tactics}

Discussing the methods of evoking fear in the players is one of the most important issues when analyzing independent horror games, due to the nature of the genre.[17] As a medium, game texts do not fall far from literature and film of the same genre; the majority of texts aim at evoking shock and disgust, introduce a disturbing enemy or an unnerving story, and rarely refrain from making use of the staple of the horror genre, dark surroundings, [18] which allows the developers to limit the player's field of view, evoking alarm and tension, both of which are crucial for the effectiveness of horror sub-genres. [19] There are also few texts, such as Stigmatized Property (2019) or Heritage (2012), which place emphasis primarily on the story instead of the aforementioned components; the atmosphere is built by allowing the player to form ideas and suspicions concerning the way the story is headed based on ominous clues, suggesting an inevitable tragic ending for the protagonist.

Very few games rely on just one strategy to scare the player. Some of the small, simple projects are restricted to the mere the presence of the monster, such as Slender: The Eight Pages or Sirenhead (2020) or to manipulating the environment around the player and nothing else, like in Precipice (2017). However, the overwhelming majority of independent horror games employs a number of scare tactics[20] ranging from the story itself, special mechanics or distinct premise to simple startle effects, and, of course, a wide variety of enemies. The term "enemy" is broad enough to apply to many game genres, but in the context of horror games, it usually refers to any kind of monster or monsters, be it supernatural entities or human monsters such as killers.[21]

[17] N. Carroll, The Philosophy of Horror, or, Paradoxes of the Heart, New York 1990, p. 30.

[18] In practice, this comes down to making the game world so dark that virtually all horror games equip the player's inventory with a flashlight or another light source so that gameplay can progress.

[19] S. Niedenthal, Patterns of obscurity: Gothic setting and light in Resident Evil 4 and Silent Hill 2, [in:] Horror Video Games..., p. 179.

[20] Scare tactics are game design elements meant to evoke fear in the player that are essential to the horror genre; they tend to manifest as diegetic and non-diegetic blind space (a situation in which the player's visual field is hidden or obscured partially or entirely), environmental threats (which usually constitute isolated and unpredictable events or effects), monstrous beings and entities which must be confronted or eluded, lacking or limited resources, or various disruptions of the integrity of the player's character. B. Perron, The World of Scary Video Games: A study in videoludic horror, New York, London 2018, pp. 115-116.

[21] N. Carroll, op.cit., p. 39. Monsters in digital games, just like in other horror texts, breach the 
The predominance of horror games featuring an enemy is indisputable; creature feature texts, such as Eyes (2013), Phobia 1.5 (2014) or Hollow Head (2019), tend to employ a very conventional approach to horror, involving facing and running from the enemy. Since the sheer presence of the enemy is by no means an original tactic for scaring the player, the creators will often introduce a monster that the player must avoid by running from it until it falls behind, or hiding from it in special places, like in Monstrum or Phobia 1,5. The player's awareness of the monster's presence invites the consideration of a legitimate embodied threat[22], allowing for the concretization of the monster character as a figure central to the horror genre[23], despite the fact that in many independent horror games, the players never actually confront the monster, but merely approximate it, seeing as there is no combat option. Some games focused solely on the enemy, such as It Lies (2019) or DIA (2019), equip the monsters with exceptional traits such as mimicking voices or the ability to trick the player. SCP: Containment Breach can, in fact, be regarded primarily as a menagerie of unique monsters with extraordinary abilities.

Another popular scare tactic often employed by indie game developers is the manipulation of the environment or employing uncanny visuals. The preferred approach is to introduce changes in the players' surroundings, ranging from minor cosmetic alterations to extensive, fundamental transformations. Minor changes can involve removing small elements of virtual environment, lighting fluctuations or acousmatic sound effects. Major changes tend to concern larger objects and structures, such as walls or doors appearing or disappearing, floating furniture or items moving when the player is not looking. The goal is to make the player disoriented and prevent them from becoming familiar with the location layout; games of this type do not require an enemy, as can be seen in the case of The Train (2013); they do, however, tend to include some storyline, conveyed most often through a pull narrative - although a push narrative can be utilized as well - as evident in Rhome (2020). While this strategy was already in use as the primary scare tactic as early as 2014, as evident in Bunker 16, it is actually a higher budget game, Layers of Fear (2016), which tends to be regarded as the title which provided the definite form to that particular convention.

Startle effects on their own can also be used as scare tactics, but without any other supporting strategy, they are merely harmless surprising sequences relying on a sudden sight or noise: an asset falling to the floor and making a sound, or a monster appearing briefly and

order of the depicted world in some way or other; they can be "categorically interstitial, contradictory..., incomplete, and/or formless" entities (p. 32), or human beings (killers, sadistic individual) nominally belonging to the natural order of the depicted world but presented in a way that makes them seem otherworldy (i.e. possessing attributes "above and beyond what one would be willing to believe of living creatures"). (p. 37).

[22] B. Perron, The survival horror: The extended body genre, [in:] Horror Video Games..., pp. 125-126.

[23] N. Carroll, op.cit., p. 16. 
disappearing without engaging the player. Games which rely primarily on startle effects are rare - Restless (2013) or Paralyzis (2020) can serve as examples - since, despite the fact that jump scares do constitute an effective way of shocking the player regardless of how immersed they are, their impact tends to decrease as the gameplay goes on. This situation can be exacerbated if, as is the case in some indie games, such as When I Sleep (2020) or 1406 (2019), those effects are applied with very little care, causing the enemies to spawn a little too early, in full view of the player, or disappear without any special effects.

Conversely, some games might reduce the player's agency and scare tactics to a minimum in order to achieve the desired effect. A text like this is Late Night Wanderer, where the player is supposed to guide the avatar home through empty streets in the middle of the night, doing nothing apart from occasionally checking their phone. Another atmosphere-driven text which features no threat, chase sequences or puzzles is The House That Hell Built (2016); however, in contrast to Late Night Wanderer, which focuses on a very mundane experience, this game makes use of very explicit imagery related to the occult. Both games exemplify an emphasis on the atmosphere over gameplay.

Premise and thematic focus
This section concerns noticeable tendencies in the premise of the gameplay and the aesthetic and narrative themes and motifs in independent horror games. These tendencies tend to correspond to ideas and themes prevalent in other horror media, encompassing a variety of concepts from monstrosities and occult to guilt-ridden human killers.

There is a number of premise types which can be distinguished among independent horror texts; the most conspicuous ones being survival, mental stereotyping, plot twists relying on the reveal of protagonist's dark past, the perspective of a killer, and the hostile takeover by the supernatural. Games which revolve around survival concern escaping from, defeating, or fending off the enemy, as can be seen in Emily Wants to Play, Escape (2020) or Vanish (2013). Every other aspect of gameplay - exploration, puzzle-solving or the story - is secondary. Texts which rely on mental stereotyping, on the other hand, use mental conditions or illness to introduce horrific content; the enemies and other scare factors are merely projections of the illness or anguish of the characters - Inmates (2017) or Psychic Isolation (2017) are examples of this approach. Conversely, the premise concerning past trauma is visible in games which depend on a sudden plot twist revealing the protagonist's guilt and responsibility. Games based on this premise, such as The House on the Hill (2020), The Survey (2016) or Dead Man's Journey (2016) structure the gameplay as a route towards the final revelation that the presence and attacks of the enemies (and related scares) are a direct consequence of the protagonist's transgression, which is usually murder or manslaughter. The next type of premise, represented by games such as Dispatch (2020), Human (2016) or Sanctified (2019), involves the 
invasion of some otherworldly entity of cosmic magnitude.[24] Such texts inevitably end with the protagonist's demise, descent into insanity, or assimilation by a hostile, unhuman entity.[25] The final concept is the premise of the player being a threat to others - in games such as Real Stories From the Grave (2020), it is the protagonist of the game that is the monster, even if other monsters are present as well; or killing human beings might also be an element of the gameplay, like in Feed Me Billy (2018), or it might be conveyed in the narrative as something that had already taken place, like in I Make Saints (2017).

Just as it is the case with gameplay premise, there are several trends in thematic focus and subject matter of independent horror games that can be distinguished. The genre naturally includes numerous themes and motifs, but a number of these are worth examining, including monsters, ghosts, the occult, traditional and Internet folklore, and children. Games whose subject matter concerns supernatural monstrosities and horrific experiments are very conventional in their approach to horror, introducing an enemy or enemies meant to intimidate the player with both appearance and behavior, as evident in It Lies or The Society. Texts revolving around hauntings and spirits, in turn, share aesthetics and structure with ghost narratives expressed in other media;[26] they feature human spirits unable to move on, or seeking revenge, as can be seen in Contemp (2017), A Girl's Fabric Face (2017) or Ghost of Tomorrow (2020). Conversely, games employing the occult setting - in the broad sense - explore the themes of esoteric practices and demonic presence. In titles such as Faith (2017), Evil Possession (2017) or Forgive Me (2020), such themes contribute to the horror atmosphere by lending the disproportionately powerful enemy the moral value of evil. The next distinct subject matter in independent horror game is folklore; some texts which follow this trend include

[24] B. Stableford, The cosmic horror, [in:] Icons of Horror and the Supernatural, vol. 1, ed. S.T. Joshi, Westport 2007, p. 71.

[25] While only some of the game texts featuring this premise contain staple traits of Lovecraftian mythos, the majority of them nonetheless display qualities characteristic of Lovecraft's concept of cosmic horror, and humanity's place in the infinite and uncaring universe. The human characters - both the avatar and other characters in the game - find themselves in a situation where they learn the nature of that universe as they are confronted with entities (deities or demons) which seem to be vaguely familiar but twisted and menacing, formed from "pieces of living bodies - tentacles, wings, eyeballs, fur, scales - mixed and matched in a mockery of flesh" (Everett and Shanks 2015: xiv); those characters then fail to "reconcile what they experience with their human categories of experience", seeing as it lies "beyond the meager bounds of human cognition, human language, and human logic" (Everett and Shanks 2015: 88), and this failure leads to a raging delirium and madness. J. Everett and J.H. Shanks, The Unique Legacy of Weird Tales: The Evolution of Modern Fantasy and Horror, New YorkLondon 2015, p. 85.

[26] The ghostly antagonists in independent game texts tend to be driven - just like ghosts in other media texts - by some sort of unfinished business: a personal affair of the deceased soul, which is most often retribution or revenge. Sometimes the games featuring this premise revolve around hauntings (where the dangerous phenomena concern anyone who comes within their range), as can be seen in Contemp or Curse (2016), or retribution directed at specific people, like in the case of The Survey or Love, Sam (2019). Cf. K. Marak, Japanese and American Horror: A comparative study of film, fiction, graphic novels and video games, Jefferson 2015, pp. 18-19. 
creatures and spirits from regular folk mythology, as can be seen in Tanggal, Llorona (2020) or The Banshee (2020), while some revolve around creepypastas, like Slender: The Eight Pages, The Momo Game (2018) or Sirenhead. In both cases, the horror effect is closely related to the specific nature of the enemy and its established presence in culture. The last distinct thematic trend worth mentioning involves children. A number of independent texts give prominence to child characters as not the enemy, but as victims in the story; occasionally, the child is the protagonist of the game. It should be noted that although the enemy can be a monster - like in Boogeyman or Night Blights - it is more often human, which is visible in games such as I Make Saints, Captivity (2019), or Mor (2019) These texts enhance the horror atmosphere by making the player uncomfortable through introducing an ethical aspect to the story.

Conclusion

It appears that among the most appealing traits of independent horror games is not only their availability, but, first and foremost, their exceptionally diverse nature. With over two hundred independent horror games compared and examined, the goal of this article was to highlight traits characteristic of the genre and draw conclusions concerning any observable trends. The independent game scene is diverse and includes a great number of innovative and quite unique game texts, and yet it is possible to distinguish a number of tendencies among the titles published between 2010 and 2020. As far as graphics and the overall aesthetic ambiance of independent texts are concerned, it is safe to say that most titles oscillate between realistic and stylized retro visuals meant to evoke nostalgia. The stories and emergent narratives recurring in independent horror games, in turn, tend to depend on environmental storytelling and a push narrative, which are strategies remarkably similar to those adopted by horror texts in other media - the exception here is the strategy of a pull narrative, favored by many developers. Conversely, the mechanics implemented in independent horror titles are decidedly a trait of games which are designed to facilitate the immersive and artistic qualities of videoludic horror. Regarding the ways in which games attempt to scare the players, the preferred options involve darkness and monsters, two elements that enjoy continued popularity among horror enthusiasts. Interestingly enough, when it comes to the actual content of the games, neither the themes nor essential ideas behind the games differ from horror narratives expressed though other media; classic motifs and subject matter revolving around monstrosities, ghosts, demons, murderers, witchcraft or folk mythology are featured in horror games to the same extent to which they are featured in horror film, literature or graphic novels. This is in not surprising, seeing as recurrent themes and premises are inherent to and expected of the horror genre; as Carroll points out, the repertoire of narrative strategies from which horror stories are 
generated is by no means extensive, nor does it teem with myriad of unpredictable storylines. [27]

Every released independent horror game contributes to the developers and players' understanding of the patterns and standards of the horror genre convention. As they pursue their ideas and combine the existing demands of that convention with new designs and experimental approaches, the developers contribute to the process of reshaping of the videoludic horror with regard to the immersion and engagement it requires; [28] furthermore, they do so not against, but according to, the logic and dynamics of the versatile and flexible medium that are digital games.[29] There is self-expression in creating independent games; even when such texts constitute "less ornate game structures than the mainstream sector," and the development time is much shorter, the authorship of the process of developing an indie title is undeniable, and so are the "designer's voice and values ... reflected in the resulting game." [30] Each independent horror game is in this sense a testimony to both the developer's perception of that genre and the direction in which they wish to explore it.

Bizzocchi J., Tanenbaum J., Well read: Applying close reading techniques to gameplay experiences, [in:] Well Played 3.0: Video games, value and meaning, ed. D. Davidson, Pittsburgh 2011, pp. 289-315

Calleja G., In-game: From immersion to incorporation, Cambridge 2011

Carroll N., The Philosophy of Horror, or, Paradoxes of the Heart, New York 1990

Everett J., Shanks J.H., The Unique Legacy of Weird Tales: The evolution of modern fantasy and horror, New York - London 2015

Fernández-Vara C., Game Spaces Speak Volumes: Indexical storytelling, <http://www. digra.org/digital-library/forums/6-think-design-play/>, accessed: 10.08.2019

Fernández-Vara, C., Introduction to Game Analysis, New York - London 2015

Garda M.B., Grabarczyk P., Is every indie game independent? Towards the concept of independent game, "Game Studies: The international journal of computer game research" 2016, vol. 16 (1), <http://gamestudies.org/1601/articles/gardagrabarczyk>, accessed: 10.08.2019

Marak K., Japanese and American Horror: A comparative study of film, fiction, graphic novels and video games, Jefferson 2015

Marak K., Markocki M., Aspekty funkcjonowania gier cyfrowych we wspótczesnej kulturze: studia przypadków, Toruń 2016

Marak K., Markocki M., Brzostek D., Gameplay, Emotions and Narrative: Independent games experienced, Pittsburgh 2019

[27] N. Carroll, op.cit., pp. 97-98.

[28] B. Perron, The World of Scary Video Games..., p. 70.

[29] M. Weise, The rules of horror: procedural adaptation in Clock Tower, Resident Evil, and Dead Rising, [in:] Horror Video Games..., 2009, p. 239.
[30] E. Westecott, Independent game development as craft, Loading... "The Journal of the Canadian Game Studies Association" 2012, vol. 7 , no. 11, pp. 78-91. 
Niedenthal S., Patterns of obscurity: gothic setting and light in Resident Evil 4 and Silent Hill 2, [in:] Horror Video Games: Essays on the fusion of fear and play, ed. B. Perron, Jefferson 2009, pp. 168-180

Perron B., Horror Video Games: Essays on the fusion of fear and play, Jefferson 2009

Perron B., The survival horror: The extended body genre, [in:] Horror Video Games: Essays on the Fusion of Fear and Play, ed. B. Perron, Jefferson 2009, pp. 121-143

Perron B., The World of Scary Video Games: A study in videoludic horror, New York - London 2018

Pinedo I., Postmodern elements of the contemporary horror film, [in:] The Horror Film, ed. S. Prince, New Brunswick 2004, pp. 85-117

Stableford B., The cosmic horror, [in:] Icons of Horror and the Supernatural, vol. 1, ed. S.T. Joshi, Westport 2007, pp. 65-96

Tringham N., Science Fiction Video Games, Boca Raton 2014

Weise, M., The rules of horror: procedural adaptation in Clock Tower, Resident Evil, and Dead Rising, [in:] Horror Video Games: Essays on the fusion of fear and play, ed. Bernard Perron, Jefferson 2009, pp. 238-266

Westecott E., Independent game development as craft, Loading... The Journal of the Canadian Game Studies Association, 7 (11) 2012. pp. 78-91

Wisker G., Horror Fiction: An Introduction, New York 2005

1406 (indie_games_studio, 2019)

1916 Der Unbekannte Krieg (Kriegsgraben und Stormvogel, 2011)

Albedo (ApeStudios, 2019)

Aloorees (dpStudios, 2019)

Amnesia: Dark Descent (Frictional Games, 2010)

Amnesia: Rebirth (Frictional Games, 2020)

Anatomy (Kitty Horrorshow, 2016)

Bad Dream: Graveyard (desertfoxsoftware, 2013)

Baldi's Basics (Basically Games, 2018)

The Banshee (Venous, 2020)

BlindSide (epicycle, 2012)

Boogeyman (Barry McCabe, 2015, Clockwork Wolf)

Buddy (surr_sloidah, 2019)

Bunker 16 (freeman08, 2014)

Captivity (DirtyLambStudio, 2019)

Close Your Eyes (Gamagam,i 2018)

Contemp (Micaka, 2017)

Cozy (Graham, 2016)

Dead Man's Journey (Turnvex, 2016)

Death: Unknown (Jakob Johansson, 2013)

Decay: The Mare ( Shining Gate Software, 2015, Daedalic Entertainment)

Deep Sleep (scriptwelder, 2013)

Despair (AkrooS, 2015)

Devout (SearchForSignsCo, 2019)

DIA (Vidas Games, 2019)

Disconnected (chrstphfr, 2017)

Dispatch (Justin Kirkwood, 2020)

The Diving Bell (Rabbit Run Games, 2020)

The Dolls: Reborn (HUSH Interactive, 2016, Forever Entertainment S. A.)

Emily Wants To Play (Shawn Hitchcock, 2015, Hitchcock Games) 
ER (Professional Villains, 2019)

Escape (David Zhang, 2020)

Evil Possession (2DragonsGames, 2017)

Expedition (WeeweeLSP, 2020)

Eyes (paulinapabis, 2013)

Faith (Airdorf Games 2017, O: Airdorf Games)

Feed Me Billy (puppet combo, 2018)

Filthbreed (bzoroza, 2019)

The Final One (Husky Dusky, 2016)

First Winter (Dan Sanderson, 2018)

Five Nights at Freddy's (Scott Cawthon, 2014)

Forbidden Siren (Sony Computer Entertainment, Inc., 2003)

Forgive Me (Churu, 2020)

Forgotten Hill Mementoes (FM Studio, 2018)

Forgotten Tapes (SethWorkStudios, 2019)

Fragments (Henry Hoare, 2019)

Frostbite (olinkalex, 2017)

Ghost of Tomorrow (Ed Lioni, 2020)

A Girl's Fabric Face (Stanislaw Truchowski, 2017)

The Glass Staircase (Puppet Combo, 2019)

Heart of the Motherland (Russian Sleep Experiment) (thuleanpanteon, 2019)

Helltown (WildArts, 2017)

Heritage (Esciron Software, 2012)

HIDE (Andrew Shouldice, 2011)

Hollow Head (Rubeki, 2019)

House (Bark Bark Games, 2020)

House on the Hill (Steppe Hare Studio, 2020)

The House That Hell Built (zach mccoy, 2016)

Human (spektraulstudios, 2016)

I Make Saints (somewhat, 2017)

I Remember This Dream (InvisiblePanda, 2015)

Ib (kouri, 2012)

Imscared: A Pixelated Nightmare (MyMadness, 2012)

Inmates (Davit Andreasyan, 2017, Iceberg Interactive)

It Lies (TooManyTeethGames, 2019)

The Janitor (VOS Gaming, 2016)

The Journal of Randolph Warren Carter (Aaron Albert, 2016)

The Last Light (kpwashere, 2016)

Last Train Home (hby, 2020)

Late Night Wanderer (Nicholas Duxbury, 2017)

Layers of Fear (Bloober Team, 2016, Aspyr)

Lea (projectHandsoap, 2014)

Llorona (gamedevboi, 2020)

Lorelai (Harvester Games, 2019, Screen 7)

Lurking (lurkinggame, 2014)

Mermaid Swamp (Uri 2013)

The Momo Game (Caffeine, 2018, Cheesecake)

Mono: I Want to Get Out (JeliLiam, 2017)

Monstrum (Team Junkfish, 2015)

The Moon Sliver (David Szymanski, 2014)

Mor (Vikid Games, 2019)

My Friend Is A Raven (Two Star Games, 2019)

Night Blights (Trapdoor Games, 2015) 
Night Ripper (Puppet Combo, 2018)

Notes of Obssession (Creaky Stairs Studios, 2016)

Now You See (Screaming Void, 2019)

One Night at Flumpty's (Clickteam, Jonochrome, 2015)

Paranormal Entities (AI Heck, 2020)

Paratopic (Arbitrary Metric, 2018)

Paralyzis (JN Squared, 2020)

Perception (The Deep End Games, 2017)

Perdita (Azaxor, 2019)

Peridium (Powerhoof, 2017)

Phobia 1,5 (Jonez Games, 2014)

Power Drill Massacre (puppetcombo, 2015)

Precipice (AkwaTeaks, 2017)

Psychic Isolation (thiefbug, 2017)

Real Stories From the Grave (DeadByte, 2020)

The Restless (Dansodic, 2017)

Rhome (SMU Guildhall, 2020)

Ripple (Proton Fox, 2020)

Room 404 (3DTM, 2016)

Roots of Insanity (Crania Games, 2017)

Rusty Lake Hotel (Rusty Lake, 2015)

Sanctified (ToothandClaw, 2019)

Sandman (Uri, 2014)

SCP: Containment Breach (Joonas Rikkonen, 2012)

Serena (Senscape, 2014)

Shiver (Kowai Sugoi Studios, 2017)

A Short Creepy Tale: 7 PM (Cellar Vault Games, 2020)

Simulacrum - Chapter One (Prymordium, 2019)

Sirenhead (UndreanedPanic, 2020)

Sightless (Digital Dracott, 2014)

Slender: The Eight Pages (Parsec Productions, 2012)

The Society (Eyesodic Games, 2016)

Sonar (Nerdy Bird, 2011)

Song of Horror, Protocol Games, 2020 (Raiser Games)

Statues (Room710 Games, 2015)

Stifled (Gattai Games, 2016)

Stigmatized Property (Chilla's Art, 2019)

Stowaway (Solar-Gate-Studios, 2013)

Submission (Corpselight, 2020)

The Survey (Robert Gammon, 2016)

The Swine (Vincent Lade, 2020)

Tanggal (Isip Games, 2018)

The Tape (Kazakov Oleg, 2015)

The Tithe (bzoroza, 2018)

Tonight You Die (Jack Squires, 2015)

The Train (The Unbeholden, 2013)

Vanish (3DrunkMen, 2013)

V.H.S: Video.Horror.Story (pinataMAN, 2017)

Wake Up ( Black Cell OG, 2016)

When I Sleep (Chixel, 2020)

Which (Mike Inel, 2010)

Witch's House (Fummy, 2012)

Wrong Floor (N4bA, 2020)

Under the Bed (Khamelot, 2018) 